\title{
Simulating epidermal growth factor receptor interaction with
} ligand

\section{Emmet McIntyre*}

\author{
Address: University of Kent, Canterbury, UK \\ Email: Emmet McIntyre* - em84@kent.ac.uk \\ * Corresponding author
}

\author{
from BioSysBio 2007: Systems Biology, Bioinformatics and Synthetic Biology \\ Manchester, UK. II-13 January 2007 \\ Published: 8 May 2007 \\ BMC Systems Biology 2007, I (Suppl I):P64 doi:I0.I I86/I752-0509-I-SI-P64
}

This abstract is available from: http://www.biomedcentral.com/I752-0509/I?issue=S I

(c) 2007 Mclntyre; licensee BioMed Central Ltd.

Understanding what causes cancer is essential in order to prevent, detect and successfully treat the disease. New computational tehniques are being developed to help research this area.

Cells are continuously exposed to a diverse range of stimuli. It is extremely important that the cell correctly interprets extra-cellular signals in order to grow correctly. Receptors from the tyrosine kinase family play a vital role. By binding to specific peptide ligands growth factor receptors are able to integrate extra-cellular signals with intracellular signalling pathways giving the cell the ability to respond to its surroundings. Ligand binding drives receptor dimerisation leading to activation of the intrinsic tyrosine kinase and autophosphorylation of specific Cterminal tyrosine residues. Each of the 4 growth factor receptor types display a distinct pattern of C-terminal autophosphorylation sites.

Epidermal Growth Factor Sim is an object-oriented approach to simulating receptor binding. The simulation models each item as an individual object and allows the interaction of these objects to propagate the emergence of the desired behaviour of the system. Object oriented design is a powerful and flexible way of modelling complex systems. In areas where defining a single algorithm would be extremely difficult or impossible, an object oriented approach can often be the answer. By modelling real-world items as "objects" and giving these objects attributes a system can be modelled and the complexity can emerge from the interaction of the objects in the system. 